\title{
Reflexiones sobre una reforma del sistema tributario nacional
}

\section{Dr. CPC Julio César Trujillo Meza}

Docente Principal de la Facultad de Ciencias Contables

\section{RESUMEN:}

El tema de la Reforma Tributaria es de palpitante actualidad dado el tiempo que se tiene en el actual sistema. El análisis busca reflexionar qué le corresponde al país, seguir con un Régimen Tributario o Reformar integralmente el Sistema y en función del nuevo Modelo Económico establecer un Nuevo Sistema Tributario Integral que forme parte de la reforma integral del Estado.

Palabras clave: Reforma Tributaria, Sistema integral tributario, desnaturalización del Sistema Tributario. 


\section{EL SISTEMA TRIBUTARIO NACIONAL}

Representa el conjunto de tributos establecidos por la legislación positiva, lo integra en su origen el artículo $74^{\circ}$ de la Constitución Política del Perú ${ }^{1}$ donde se instauran los principios constitucionales de la tributación; adicionalmente, existen otros artículos contenidos en la Constitución y vinculados con los efectos tributarios. A ello debemos agregarle el Decreto Legislativo No 771, el Código Tributario, el Decreto Legislativo No 816, modificado por los Decretos Legislativos Nros. 953, 969 y 981, que contienen el Título Preliminar de aplicación de principios y los cuatro (4) Libros que contienen la normatividad legal de aplicación de principios a todos los tributos existentes, luego la Ley Penal Tributaria normada a los efectos del control de la evasión y la informalidad traducida en muchos casos en la llamada Defraudación Tributaria como tipo penal. Finalmente, dentro del Sistema Tributario Nacional no puede dejar de mencionarse la integración de la Administración Tributaria a nivel nacional como organismo aplicador, controlador, fiscalizador y recaudador de los tributos.

Nos preguntamos: ¿Tenemos un Sistema Tributario Nacional o un Régimen Tributario Nacional?

a. Sistema tributario. Es el conjunto de normas y principios tributarios diseñados sistemáticamente, coherentes y definidas en el tiempo que proporcionan seguridad jurídica tanto a los contribuyentes por la consideración de sus costos tributarios a todos los efectos, como la seguridad de recaudación para el Estado y ser incluido en el presupuesto público a fin de cumplir la finalidad del Estado para con la sociedad. b. Régimen tributario. Es un conjunto de normas tributarias establecidas por el Estado con objetivos concretos, a fin de cumplir con los objetivos delineados para estos efectos.

c. Nuestro Sistema Tributario Nacional pretendió ser un sistema hasta el gobierno del presidente Fernando Belaunde Terry; sin embargo, con el presidente Alberto Fujimori, al dictarse los Decretos Legislativos Nros. 771; 774; 816; 821, entre otros, y la cantidad de modificaciones la distorsionaron totalmente como Sistema para pasar a ser un Régimen por la desnaturalización del Impuesto a la Renta de las personas naturales y de las personas jurídicas o empresas, dentro de otras razones. El régimen del presidente Alberto Fujimori tuvo como objetivo recaudar y para ello estableció un nuevo Código Tributario con facultades discrecionales en varios artículos y con presunciones que en muchos casos son absolutas; es decir, no admiten pruebas en contrario, afectando el principio constitucional de derecho a la defensa.

d. El Sistema se ha desnaturalizado básicamente, entre otras razones, por lo siguiente:

d1. El desconocimiento de un modelo económico y una política económica coordinada con una política fiscal que asegure las rentas, patrimonios y consumo que el modelo económico pueda proporcionar.

d2. El establecimiento de tributos antitécnicos que luego fueron declarados inaplicables por el Tribunal Constitucional.

d3. El mantenimiento de algunos tributos que son cuestionables por falta de adecuación a los principios tributarios y de poco o nulo interés tributario en la recaudación, pero distorsio-

1 Constitución Política del Perú de 1993. 
nante en el sistema y engorroso para los contribuyentes.

d4. El establecimiento e incremento de las formas o modalidades de aplicación de las presunciones en el Código Tributario y en la aplicación de otros tributos como en el Impuesto a la Renta y en el Impuesto General a las Ventas y otras normas.

d5. La permanencia de las facultades discrecionales, tanto en el Código Tributario como en otras normas tributarias, no adecuándose a la mayoría de Sistemas Tributarios de América Latina. El Código Tributario Modelo para América Latina formulado por el CIAT $^{2}$ contiene solo cuatro casos de presunción y no contiene la famosa «discrecionalidad», sino que la recomendación es que sea reglada (reglamentada).

d6. Estas razones hacen que el actual régimen, si bien puede ser recaudatorio, no tiene un sistema técnico, jurídico, de principios y de correcciones a la estructura. Ante ello, ¿qué alternativa debe plantearse?, ¿una reforma o una reestructuración?

\section{LA REFORMA}

A decir de Guillermo Cabanellas, la reforma implicaría una nueva forma, un cambio, una modificación, variación, corrección o enmienda ${ }^{3}$.

De 1990 a la fecha se han producido modificaciones al Régimen Tributario y no se ha podido llegar a estructurar un sistema tributario que de alguna forma mejore el actual régimen; por el contrario, se dictan normas de orden legal que hacen cada vez más complicado su aplicación; más aún, teniendo en cuenta la gran cantidad de resoluciones de Superintendencia que inciden en lo formal y en el procedimiento, aunque también inciden en lo sustancial cuando modifican aspectos sustantivos de la ley.

Podemos afirmar sin equivocarnos, que la reforma o modificación del régimen a la fecha no ha dado resultados, se viene haciendo más frondosa la legislación tributaria y cada vez es más difícil su aplicación y ello lleva con mayor velocidad a la informalidad y a la evasión tributaria; por lo tanto, si una reforma o modificación del sistema no ha dado resultados en estos más de diez años, se tendría que pensar con mayor seriedad en el diseño de un nuevo Sistema Tributario.

\section{REESTRUCTURACIÓN DEL SISTEMA}

Este concepto es compartido por muchas instituciones a nivel nacional en el afán de mejorar la tributación en el país y hacerlo más razonable, donde primen los principios tributarios constitucionales y los criterios racionales introducidos a través de las leyes, a fin de alcanzar un real equilibrio entre el Estado y el contribuyente, y se dejen de lado los decretos legislativos y el Congreso asuma su función de legislar.

Se requiere un estudio y un nuevo enfoque de los principios tributarios contenidos en la Constitución, se necesita mejores normas que equilibren la relación jurídica tributaria, y cambiar sustancialmente el Sistema de Impuesto a la Renta, el Sistema del Impuesto

2 Centro Interamericano de Administraciones Tributarias, Artículo 73o p. 71.

3 Cabanellas, Guillermo: Diccionario de derecho usual, p. 506. 
General a las Ventas; se demanda otras leyes sectoriales y otros tributos que concuerden con las Normas Internacionales de Información Financiera (NIIF's antes NIC's) a fin de acercarla a las normas tributarias y lograr una mejor concordancia; elaborar normas adecuadas al régimen de precios de transferencias que, al parecer, pueden modificar sustantivamente el control tributario en la medida que su reglamentación se adapte.

Estos aspectos hacen que todas las instituciones involucradas puedan participar en la formulación de un nuevo Sistema Tributario. Instituciones gremiales como la Cámara de Comercio, Confiep, ADEX, Sociedad Nacional de Industrias, Cámara Peruana de la Construcción, entre otras; igualmente, pueden ser las instituciones dedicadas a la investigación y difusión del aspecto tributario como el Instituto Peruano de Derecho Tributario (IPDT); el Instituto Peruano de Investigación y Desarrollo Tributario (IPIDET), así como los Colegios Profesionales, entre ellos el Colegio de Abogados de Lima, Colegio de Contadores Públicos de Lima, Colegio de Economistas y Colegio de Administradores.

En el mes de agosto del presente año, el Colegio de Abogados de Lima llevó a cabo el Congreso Nacional de Abogados y la comisión encargada del tema tributario llegó a recomendar un cambio estructural del llamado Sistema Tributario Nacional.

\section{CONCLUSIÓN}

Considero que es necesario que se produzca una Reforma Tributaria del Estado y se incluya en ella una reestructuración integral, asimismo, se formule un nuevo Sistema Tributario Nacional; sin duda que para ello será necesario un cambio de la Constitución actual, de modo que haya una mayor seguridad jurídica de los contribuyentes, un mayor equilibrio entre contribuyente y Estado, un sistema duradero que proporcione los ingresos necesarios para el Presupuesto General de la República y pueda cumplir su objeto de lograr un mejor bienestar para toda la sociedad peruana.

\section{REFERENCIAS}

Constitución Política del Perú. 1993.

Cabanellas Guillermo. Diccionario de Derecho Usual, Tomo III, 6ta. ed., Buenos Aires, 1968.

Centro Interamericano de Administraciones Tributarias (CIAT). Código Tributario Modelo para América Latina. Panamá, 1997.

Decreto Legislativo № 816 (20.04.1996), Código Tributario. 